\title{
BIBLIOTECA ESCOLAR E MEDIAÇÃO DE LEITURA: UMA PROPOSTA DE FICHAS PEDAGÓGICAS DE REGISTRO DOS LIVROS
}

\author{
BIBLIOTECA ESCOLAR Y LA MEDIACIÓN DE LECTURA: \\ UNA PROPUESTA DE HOJAS DE REGISTRO \\ BIBLIOGRÁFICO
}

\begin{abstract}
Rovilson José da Silva - rovilson@uel.br Doutor em Educação pela Universidade Estadual Paulista (UNESP). Professor do Programa de Pós-Graduação em Educação e do Departamento de Educação da Universidade Estadual de Londrina (UEL).

Gisleine de Oliveira Tenório - gisleinetenorio@gmail.com Graduada em Letras Vernáculas e Especialista em Gestão de Biblioteca

Escolar pela Universidade Estadual de Londrina (UEL).
\end{abstract}

\section{RESUMO}

Introdução: Este artigo aborda a formação social e acadêmica do educador de Biblioteca Escolar e sua contribuição no desenvolvimento de práticas de mediação de leitura para a formação do leitor, por meio da biblioteca escolar.

Objetivo: Verificar como a biblioteca escolar, sua organização pedagógica e a contação de histórias contribuem com a formação de leitores.

Metodologia: A pesquisa é de cunho bibliográfico com o método documental baseada em documentos pessoais, escritos e em documentos oficiais. Fundamenta a pesquisa as concepções de: Silva, Lajolo, Zilberman que conceituam leitura; documentos da UNESCO e Barbosa et. al. a respeito da organização da Biblioteca Escolar.

Resultados: Como resultado dessa pesquisa obteve-se uma ficha de registro bibliográfico como auxílio na formação contínua do educador de biblioteca para que todos os educadores escolares possam utilizar os livros em sala de aula no momento de contação de histórias e, portanto, ampliar sua prática pedagógica de mediação de leitura.

Conclusões: Conclui-se que o educador da biblioteca escolar tem a função mediar a aprendizagem do aluno, estimulando-o a ler e apresentando-lhe literaturas que contribuam 
para seu amadurecimento como leitor, cabe ressaltar que o ambiente físico da biblioteca deve estar adequado para receber este leitor para que propicie a aproximação do leitor com o livro.

Palavras-chave: Biblioteca escolar. Mediação de leitura. Formação do leitor. Registro bibliográfico.

\section{INTRODUÇÃO}

Ler está além do decodificar palavras, pois o conceito de leitura atual é baseado nas condições sociais do homem, sendo produto da interação entre o sujeito leitor e o texto. Nesse contexto, a função da escola é, dentre outras, promover estratégias e condições para que ocorra o crescimento individual do leitor, despertando-Ihe interesse pela leitura e escrita e, principalmente, aptidão e competência nestas práticas. Para isso é importante que a biblioteca seja uma aliada nesse processo, pois ela tem grande capacidade para oferecer atividades relacionadas à leitura e, portanto, um instrumento de apoio técnico-pedagógico capaz de formar leitores.

A biblioteca escolar oferece livros diversificados, literários e não literários, jornais, gibis e revistas que contribuem para a formação cultural e informacional do indivíduo, constituindo-se de uma valiosa ferramenta para a educação, pois por meio dela é possível preparar os alunos para uma formação constante, fornecendo-lhes condições reais de aprendizagem, transformando-os em sujeitos ativos do seu próprio processo de conhecimento.

Se a biblioteca escolar não for um local que é frequentada pelos alunos e com uso de seu acervo, de nada adiantará ter o profissional, o acervo e o espaço físico da biblioteca em uma escola, será apenas um desperdício. Por isso é necessário que o profissional que atua na biblioteca escolar faça mediação ${ }^{1}$ de leituras, que ele possa instigar o interesse nos usuários a fim de que frequentem o espaço e possam criar o gosto com a leitura.

\footnotetext{
${ }^{1}$ Sendo esta: "[...] toda ação de interferência - realizada pelo profissional da informação -, direta ou indireta; consciente ou inconsciente; singular ou plural; individual ou coletiva; que propicia a apropriação de informação que satisfaça, plena ou parcialmente, uma necessidade informacional." (ALMEIDA JÚNIOR, 2009, p. 4).
} 
Deste modo, é importante refletir que o educador da biblioteca ${ }^{2}$ escolar tornese um dos responsáveis em aproximar os alunos das práticas de leitura. Também é necessário compreender o espaço da biblioteca e sua relação com o ambiente escolar e as práticas de leitura de forma a intensificar suas contribuições para a formação dos alunos.

Interessante é que o profissional de biblioteca possa desenvolver ferramentas para que todos os educadores possam se tornar mediadores de leitura. Neste sentido, o trabalho em questão abrange a elaboração de estratégias de mediação de leitura por meio de fichas de leitura que orientem o educador quanto à temática e recursos pedagógico que podem ser utilizados em sala para se desenvolver a Hora do Conto.

\section{A BIBLIOTECA ESCOLAR E A MEDIAÇÃO DE LEITURA}

Antes de abordar a biblioteca escolar e os processos de mediação de leitura é importante compreender o espaço em que este tipo de biblioteca se encontra: a escola.

Nos Parâmetros Curriculares Nacionais de Língua Portuguesa (BRASIL, 1997) que orientam os currículos do Ensino Fundamental e Médio, há um enfoque no ensino da leitura, - principalmente no capítulo "Os conteúdos de Língua Portuguesa no Ensino Fundamental" - que estará presente durante os onze anos de estudo nesses dois níveis, como um dos tópicos de ensino da disciplina de Língua Portuguesa, mas não apresenta um projeto pedagógico definido e viável, que contribui para o desenvolvimento do ensino da leitura. Desta maneira, professores até sabem o que deve ser feito, mas não sabem como fazê-lo.

Por não entender qual a melhor forma de se trabalhar a leitura no ambiente escolar, persiste a ideia de que o aluno deve fazer a leitura de livros para que haja uma prova sobre o conteúdo do mesmo.

A ideia de que temos que fazer alguma coisa com o livro após tê-lo lido levou muita gente, apesar de bem intencionada, a criar um dos vícios pedagógicos mais difíceis de ser removidos ou alterados: aplicação de prova sobre o texto literário lido. Essa mesma prova tem

\footnotetext{
${ }^{2}$ Nesta pesquisa entende-se que o educador da biblioteca é aquele responsável pelo acervo bibliográfico, possuindo ou não, formação na área de Biblioteconomia.
} 
afugentado, calma, metódica, cotidiana e infalivelmente, milhares de crianças e jovens do prazer da leitura. (GARCIA, 1992, p. 52).

Muitos professores se tornam reféns do livro didático, pois imaginam encontrar todo o saber necessário para sua prática pedagógica e utilizam o texto literário como apenas um pretexto para realizar atividades didáticas, isso não ocorre apenas nas disciplinas de Língua Portuguesa, mas em todas as disciplinas do currículo. Essa prática é muito comum na realidade escolar, resultando em alunos que não gostam ou, pior, não sabem ler um texto.

O texto não é pretexto para nada. Ou melhor, não deve ser. Um texto existe apenas na medida em que se constitui ponto de encontro entre dois sujeitos: o que escreve e o que lê; escritor e leitor, reunidos pelo ato radicalmente solitário da leitura, contrapartida do igualmente solitário ato da escritura. (LAJOLO, 1986, p. 52).

A aproximação do aluno com o texto, principalmente o literário, não deve partir da obrigatoriedade, o aluno deve ter autonomia para escolher suas leituras e rebelar-se contra uma leitura que ele não tem afinidade.

É necessário que a escola brasileira seja um lugar que propague a leitura por fruição e não apenas aquela obrigatória e que os alunos possam ter acesso fácil a obras diversificadas, sem restringir a leitura a textos do livro didático ou leituras voltadas para algum tipo de avaliação subsequente. Para Zilberman (2003, p. 16)

[...] a sala de aula é um espaço privilegiado para o desenvolvimento do gosto pela leitura, assim como um campo importante para o intercâmbio da cultura literária, não podendo ser ignorada, muito menos desmentida sua utilidade. Por isso, o educador deve adotar uma postura criativa que estimule o desenvolvimento integral da criança.

Neste caso não só a sala de aula, mas principalmente, a biblioteca deve despertar o gosto pela leitura, sendo parte integrante do processo educativo conforme afirma o Manifesto da IFLA/UNESCO sobre a biblioteca escolar. Neste documento há afirmação de que este gênero de biblioteca:

[...] proporciona informação e ideias fundamentais para sermos bem sucedidos na sociedade atual, baseada na informação e no conhecimento. A biblioteca escolar desenvolve nos estudantes competências para a aprendizagem ao longo da vida e desenvolve a imaginação, permitindo-lhes tornarem-se cidadãos responsáveis. (IFLA, 2013, Não paginado). 
A biblioteca escolar não é apenas um local onde se armazena, organiza e se empresta livros, também não basta ter um acervo atualizado e ser bem localizada, mas precisa ter um profissional que favoreça o encontro entre o livro e o leitor.

\subsection{O educador que atua na biblioteca escolar}

O processo de registro, preservação e empréstimo dos volumes, na maioria das vezes, é feito por um educador que não é graduado ou possui cursos na área de biblioteconomia. Isso não significa que o profissional é menos seja capacitado para a função, pois, antes de ter algum curso na área o responsável pela biblioteca escolar deve ter características que garantam a realização de manutenção e catalogação eficaz do acervo, bom atendimento ao usuário e incentivo à leitura.

O educador da biblioteca "[...] deve apresentar qualidades que o possibilite promover de fato a leitura. Para que deste modo, os valores e conhecimento de nossa sociedade cheguem até as crianças." (MARTINS; BORTOLIN, 2006, p. 35). Garcia (1992, p. 68) complementa que o educador da biblioteca escolar deve ser "[...] uma pessoa com formação pedagógica, capaz de conhecer livros e leitores, seus interesses; um leitor que sobretudo, goste profissionalmente de livros e leitura." Desta maneira, observamos que o profissional-leitor compreende a importância da leitura para a formação humana e de forma intrínseca desperta o gosto pela leitura em seus alunos e desenvolve ações para que essa prática seja estimulada. Cabe, aqui, reforçar que este educador pode ou não ter formação acadêmica específica em biblioteconomia, mas que as características acima são inerentes à atuação profissional em biblioteca.

Para isso, o educador que atua na biblioteca escolar deve ser aquele que medeia a leitura, ou seja, aquele que aproxima o leitor do livro. Barros (1995, p. 56), afirma que "[...] mediar leitura, na biblioteca, significa fazer fluir material de leitura até o leitor, eficiente e eficazmente, formando e preservando leitores. Significa uma postura ativa, de acordo com uma biblioteca moderna e aberta." Esta mediação está presente em todas as atividades realizadas pelo educador da biblioteca, sendo implícita ou explícita, pois mediar é fazer com que a informação faça sentido para quem a recebe e deixe de ser apenas um signo, levando os usuários a enriquecer seus conhecimentos por meio da transmissão da informação. 
O educador que atua na biblioteca da escola deve enxergar a educação em seu sentido amplo, estimulando a formação de hábitos e atitudes dos alunos, possibilitando a todos os estudantes o acesso ao conhecimento; reforçando o processo de leitura para que, por meio dela, o indivíduo amplie seus conhecimentos, bem como suas capacidades críticas e reflexivas.

Martins e Bortolin (2006, p. 71) afirmam que o educador da biblioteca

[...] além de respeitar as características e as necessidades dos usuários de hoje, deve estabelecer limites, sem autoritarismo, para que a criança e o adolescente possam ter, não apenas livre acesso às estantes, mas também espaço de liberdade para imaginar, indagar e inquietar, maravilhando-se com suas descobertas [...]

Uma das ações do educador da biblioteca é instigar a leitura nos usuários, tornando a história interessante para o leitor, discutindo os livros e artigos de periódicos, realizando questionamentos para estimular a criticidade do leitor, mostrar os benefícios que a leitura oferece e o poder de transformação que ela tem na vida das pessoas, estando assim inserido na comunidade escolar.

Silva (1991) acredita na parceria entre o profissional atuante em biblioteca escolar e professor quando se trata de leitura, cada um em uma função específica, o primeiro deve priorizar as condições para que a criança aprenda a ler e o segundo deve estar integrado ao professor, cooperando para que a criança desenvolva suas capacidades de leitura, e pratique em sua vida o ler para aprender.

Com os adolescentes, o educador da biblioteca deve estar atento às preferências literárias de cada leitor, procurar estratégias para satisfazê-las. Para formar leitores, é importante dispensar as leituras impostas, respeitando as opiniões e o gosto dos mesmos. Não se deve obrigar e cobrar leituras, pois isso faz com que o sujeito se afaste ainda mais da leitura.

Estar em parceria com os professores e o planejamento escolar é de suma importância. Com as crianças, existe a necessidade do ambiente da biblioteca ser convidativo à leitura e agradável, que o mediador seja uma pessoa ágil e estimule a imaginação das crianças, para que elas possam aprimorar sua capacidade intelectual.

Esse processo de mediação de leitura é fácil de ser realizado, pois necessita de poucos recursos e pode se desenvolver das mais diversas maneiras, mas não é por ser de fácil execução que a mediação de leitura deve ser feita de forma 
insatisfatória. Esta prática deve ser pautada na importância da leitura e a conscientização da importância do trabalho do mediador, bem como quais as leituras que serão mediadas.

Para que ocorra uma ressignificação da leitura na escola é importante que a biblioteca seja uma aliada pedagógica, pois é a partir dela, do profissional responsável e da disponibilidade do acervo que se consegue atingir os objetivos de motivar os alunos a serem independentes e autônomos em suas leituras.

É preciso que o educador da biblioteca se envolva com a comunidade escolar, estabelecendo parcerias com os professores, desenvolvendo propostas para formação do leitor e promoção da leitura e acesso à cultura. Silva (2003, p. 9192) fala sobre a importância dessa parceria:

[...] cabe a esses dois profissionais - professor e bibliotecário - ler e fazer ler. Repetindo: cabe ler e fazer ler. Isto quer dizer que, para abraçar qualquer dessas duas profissões, o sujeito tem que ser leitor, encarnando em si as práticas de leitura como um valor absoluto e, por ter que fazer ler, tem que projetar e inculcar esse valor em todos os membros da sua comunidade através de projetos, programas e ações. [...] Quando os dois (professor e bibliotecário), atuando juntos, construírem boas estradas para que o leitor efetivamente dialogue assiduamente com esse "mestre dos mestres" [ivro], ou seja, com aquele que por si só ensina sem a intermediação de mais ninguém, então resultará desse processo a inserção da criança e do jovem num outro patamar sócio-educacional, qual seja o patamar da independência e autonomia em leitura.

As atividades desenvolvidas devem aproximar o aluno-leitor e o texto e para isso é crucial conhecer a comunidade escolar e propiciar atividades que estimulem a leitura "livre" desprendida da cobrança de leitura para aquisição de conteúdos ou normas gramaticais.

A fim de aproximar os usuários do acervo, é importante criar alternativas para que esse acesso se torne mais fácil, assim, criou-se fichas de registro dos livros de forma a sistematizar alguns elementos importantes para o professor utilizar em sala de aula a fim de estimular os alunos a ler.

\subsection{Fichas de leitura - organização pedagógica da Hora do Conto}

Um aspecto fundamental para o incentivo à leitura é o planejamento das atividades que serão desenvolvidas no ambiente da biblioteca, atentando-se para os 
horários e espaços onde elas acontecerão. Para Menegola e Sant'Anna (2001, p. 25):

\begin{abstract}
Planejar o processo educativo é planejar o indefinido, porque educação não é o processo, cujos resultados podem ser totalmente pré-definidos, determinados ou pré-escolhidos, como se fossem produtos de correntes de uma ação puramente mecânica e impensável. Devemos, pois, planejar a ação educativa para o homem não impondo-Ihe diretrizes que o alheiem. Permitindo, com isso, que a educação, ajude o homem a ser criador de sua história.
\end{abstract}

Desta maneira, percebemos que o planejamento serve para nortear a prática do educador, mas ele não deve se prender somente a ele. O planejamento deve ser adaptado ao longo do desenvolvimento da ação para se adequar ao seu público. Para Silva (1991, p. 42)

Essencialmente, educar/ensinar é um ato político. Entendamos bem essa proposição: a essência política do ato pedagógico orienta a práxis do educador quanto aos objetivos a serem atingidos, aos conteúdos a serem transmitidos e aos procedimentos a serem utilizados, quando do trabalho junto a um determinado grupo de alunos.

O planejamento possibilita observar as ações realizadas, os objetivos alcançados, as adaptações feitas ao longo do percurso e serve como um registro das atividades, observando o que pode ser feito para melhorar a aplicação daquela atividade em outra oportunidade.

Além disso, é necessário estabelecer as normas que regem o espaço e também organizá-lo de forma que os alunos possam ter acesso ao acervo e ter a liberdade de consultá-lo e conhecê-lo antes de realizar o empréstimo. O acervo deve ser variado e composto por revistas, gibis e livros de diversas temáticas que se adequem à faixa etária do público atendido. Para Bicheri e Almeida Júnior (2013, p. 52):

a contribuição, está nas 'entrelinhas' da mediação, da intervenção deste profissional na escola, no seu engajamento e comunicação na comunidade, como trabalhar em parceria, sua maneira de organizar o espaço da biblioteca (organização do ambiente e tempo para frequência e leitura), ao receber seus usuários, na demonstração do amor pela leitura, na indicação de leituras, na forma em que lê uma história, como conta uma história e a escuta, ao apresentar um autor e se apresentar como bibliotecário leitor, não desistindo frente às dificuldades encontradas e criando oportunidades de leitura frente à vida escolar. 
Todos que frequentam o ambiente da biblioteca devem ser estimulados, inclusive, os educadores a fim de que utilizem os materiais disponíveis. Mesmo assim, ainda existe dificuldade em localizar os materiais nas estantes e as tabelas de classificação não são acessíveis para quem não tem conhecimento específico sobre elas. Uma maneira de mudar a forma com que os usuários utilizam a biblioteca é fornecer instrumentos para que esses possam utilizar os materiais bibliográficos com facilidade.

$\mathrm{Na}$ biblioteca, o profissional pode ajudar a aproximar os leitores dos livros, sua utilização em sala de aula e também movimentar o ambiente da biblioteca para que os educandos e educadores possam frequentar assiduamente a biblioteca e conhecer outros volumes, para facilitar o acesso ao livro é interessante começar pelo registro dos volumes na base de dados e disposição dos livros nas estantes, separar os livros por assunto, tema, faixa etária é outra sugestão que pode dar bons resultados. Barbosa et al. (2005, p. 1) afirmam que:

Quanto mais simples a identificação das obras ficcionais, quanto mais independentes a busca e a seleção pelos usuários, maior o uso das bibliotecas e do acervo. Convenhamos nas estantes, os números cabalísticos das lombadas acham-se longe de possuir um caráter comunicativo desejável, por mais transparente e clara que seja a sua lógica... para nós, profissionais da área.

Acredita-se que os sistemas de classificação mais utilizados em bibliotecas a Classificação Decimal Universal (CDU) e a Classificação Decimal de Dewey (CDD) - podem ser utilizados nas bibliotecas e que é interessante o contato com esses sistemas para que as crianças e adolescentes se acostumem com os códigos, mas é fundamental que o acesso ao livro possa ter outro sistema de apoio que priorize o contato do leitor com o livro de forma a facilitar este acesso e sua familiarização.

Uma maneira de facilitar esse processo é desenvolver fichas de registro dos livros (Quadro 1) que possam tornar o acesso mais pedagógico e fácil de encontrar os temas que os educadores procuram, auxiliando-os na utilização dos livros como um recurso didático.

Esta ficha serve de apoio didático ao professor que pode consultar os temas, um resumo da história e, ainda, dispõe de recursos para a realização de contação de histórias, facilitando o trabalho do educador em selecionar os materiais para desenvolver estas atividades. Na ficha elaborada criou-se campos para que o 
educador localize a história, temas transversais, objetivos, enredo, personagens, clímax, início da história, recursos e a bibliografia. Para Barbosa, Mey e Silveira (2005, p. 2):

[...] os catálogos de assuntos para as obras de ficção, quando existem, limitam-se à recuperação pela nacionalidade do autor ou pelo grupo linguístico das literaturas (literatura inglesa, literatura francesa, literatura brasileira etc.), mostrando-se, na prática de pouca valia. Em sã consciência, respondamos quantos leitores, até hoje, chegaram a nossa biblioteca e pediram "um livro de literatura alemã"? Mesmo assim, Brecht e Goethe despertam interesse considerável. Se cabe derrubar os muros, acabar com as barreiras, comecemos pelos catálogos e pelas lombadas dos livros.

Desta maneira, repensou-se a catalogação dos volumes, enfatizando os educadores que trabalham no ambiente escolar e constantemente necessitam de uma ficha que auxiliasse o educador a selecionar histórias para a Hora do Conto, a fim de tornar a pesquisa de livros por temáticas e por recursos mais fácil e mais ágil. Com estas fichas, o educador poderá localizar os livros por assunto e ainda ter um apoio ao desenvolver a contação de histórias em sala, afinal, a ficha fornece recursos e maneiras de se introduzir uma história. Barbosa, Mey e Silveira (2005, p. 1) menciona que "[...] transformar as bibliotecas em locais agradáveis, acolhedores, onde o leitor possa encontrar rápida e facilmente as obras desejadas."

Simão, Schercher e Neves (1993) corroboram "O sucesso desta interação biblioteca-usuário depende em grande parte da maneira como a biblioteca está instalada e como seu mobiliário e equipamento estão distribuídos. Depende também da forma como os recursos de informação estão identificados e ordenados nas estantes."

A classificação dos materiais bibliográficos deve estar completamente ligada com as necessidades e expectativas dos usuários fornecendo a eles maior facilidade para encontrarem o que desejam, por isso, esta ficha resume os principais pontos do livro apresentando de maneira geral os pontos importantes da história, seus personagens, os temas abordados e apresenta sugestões de recursos para serem confeccionados e utilizados no momento da contação de histórias, bem como formas de iniciar a história para que o educador comece a leitura de forma lúdica. 
Rovilson José da Silva; Gisleine de Oliveira Tenório

Biblioteca escolar e mediação de leitura: uma proposta de fichas pedagógicas de registro dos livros

Quadro 1 - Ficha pedagógica de registro bibliográfico para a realização da Hora do Conto

\begin{tabular}{|l|l|}
\hline Título & Obax \\
\hline $\begin{array}{l}\text { Determinantes } \\
\text { sociais }\end{array}$ & Pluralidade Cultural, Respeito às diferenças. \\
\hline $\begin{array}{l}\text { Objetivos do } \\
\text { Educador }\end{array}$ & $\begin{array}{l}\text { - Crianças de 02 a 07 anos } \\
\text { - Transmissão de valores como: respeito. }\end{array}$ \\
\hline $\begin{array}{l}\text { Tipo do } \\
\text { Enredo }\end{array}$ & Conto popular africano \\
\hline $\begin{array}{l}\text { Personagens } \\
\text { Principais }\end{array}$ & Obax \\
\hline $\begin{array}{l}\text { Personagens } \\
\text { Secundários }\end{array}$ & Elefante \\
\hline $\begin{array}{l}\text { Cenário ou } \\
\text { Lugar }\end{array}$ & Vilarejo africano. \\
\hline $\begin{array}{l}\text { Ponto } \\
\text { Culminante }\end{array}$ & Quando Obax disse que presenciou chuva de flores. \\
\hline Desfecho & $\begin{array}{l}\text { O baobá do quintal faz com que as flores caiam e } \\
\text { acontece a chuva de flores que Obax tanto falava. }\end{array}$ \\
\hline $\begin{array}{l}\text { Recursos } \\
\text { Utilizados }\end{array}$ & $\begin{array}{l}\text { Folhas de E.V.A., Flores de E.V.A, estrelas de papel } \\
\text { laminado e avental. }\end{array}$ \\
\hline $\begin{array}{l}\text { Conversa } \\
\text { Inicial }\end{array}$ & $\begin{array}{l}\text { Hoje eu vou contar uma história de uma menina que } \\
\text { assim como eu adorava contar histórias... }\end{array}$ \\
\hline $\begin{array}{l}\text { Início da } \\
\text { história }\end{array}$ & Utilização do Pin \\
\hline Referencia & NEVES, André. Obax. São Paulo: Brinquebook, 2010. \\
\hline
\end{tabular}

Fonte: Dados da pesquisa

Este trabalho com as fichas foi desenvolvido em uma Biblioteca Escolar de uma escola fundada em 1988, com 27 anos de existência, implantada na cidade de Londrina - PR, na Zona Sul e dispõe de educação Infantil, Ensino Fundamental I e Ensino Fundamental II, com aproximadamente 300 alunos matriculados que são atendidos no período Matutino e Vespertino. O projeto da Hora do Conto era semanal, realizado todas as sextas-feiras para os alunos de El 2 a $2^{\circ}$ ano do Ensino Fundamental I. 
Ao utilizar estas fichas, desenvolveram-se novas histórias, atentando-se para que a Hora do Conto semanal sempre apresentasse uma variedade de recursos como: fantoches, teatro, teatro de sombras, leitura de imagens, participação dos alunos nas histórias. Tornando esse momento dinâmico e criativo para as crianças e para a educadora da biblioteca.

Além disso, ao observar o trabalho realizado nas conotações anteriores, buscou-se iniciar as histórias de maneira diferenciada, com musicalizações e brincadeiras a fim de tornar este momento mais lúdico para os educandos. Depois da realização da atividade as fichas eram guardadas como forma de registro da atividade, juntamente com fotos do momento de sua realização, pois

\begin{abstract}
O registro ajuda a guardar na memória fatos, acontecimentos ou reflexões, mas também possibilita a consulta quando nos esquecemos. Este "ter presente" o já acontecido é de especial importância na transformação do agir, pois oferece o conhecimento de situações arquivadas na memória, capacitando o sujeito a uma resposta mais profunda, mais integradora e mais amadurecida, porque menos ingênua e mais experiente, de quem já aprendeu com a experiência. Refletir sobre o passado (e sobre o presente) é avaliar nas próprias ações, o que auxilia na construção do novo. E o novo é a indicação do futuro. É o planejamento. (WARSCHAUER,1993, p. $62)$.
\end{abstract}

Percebemos que o registro auxilia na formação permanente do profissional e possibilita a junção consciente da prática e da teoria permitindo, ao educador, fazer e aprender com o fazer.

\title{
3 CONSIDERAÇÕES FINAIS
}

Ao estimular a reflexão acerca dos textos lidos, sejam eles literários ou não, o professor propicia a aquisição de cultura escrita pelos alunos. Esta deve ser complementada sempre com outras leituras além das leituras disponíveis nos livros didáticos ou materiais pedagógicos, é por isso que o educador da biblioteca torna-se um parceiro neste momento, auxiliando os professores a indicarem leituras diversas aos alunos, desenvolvendo propostas de promoção à leitura e formação do leitor.

O educador da biblioteca é um aliado do educador regente e, portanto, caberá a ele receber bem os usuários, auxiliando-os, sugerindo leituras diversas, e 
fornecendo meios para que o usuário se torne um leitor autônomo. Essa autonomia deve ser despertada em todos os alunos, não importa com qual idade ele tenha tido contato com os livros, por isso o educador da biblioteca torna-se aquele que capta os interesses do leitor em formação a fim de lhe mediar leituras que se adequem ao nível de leitura do usuário, para que a proximidade com os livros seja a mais prazerosa possível.

Quando se trata de crianças, a proximidade com histórias infantis gera uma identificação com os sentimentos dos personagens, que experimentam simbolicamente as questões da vida como morte, sofrimentos, ajudando a criança a se desenvolver e a amadurecer psicologicamente.

Para que isso ocorra de maneira eficaz, é necessário atentar-se a todos os fatores que interferem nas estratégias de se formar um leitor. $O$ ambiente deve ser 0 primeiro a propiciar a qualidade no fomento à leitura: bem arejado, com um mobiliário adequado às idades que frequentam o espaço, o acervo deve ser diversificado priorizando o contato do aluno com o livro, é importante ter uma rotina estabelecida para que todos os alunos da escola possam usufruir da biblioteca, conhecendo seu acervo e participando de atividades dentro da biblioteca a fim de se familiarizar com o espaço e suas regras de convivência.

É necessário o planejamento da hora do conto, este momento deve ser feito semanalmente, abrangendo todos os alunos da escola principalmente as crianças as quais estão em fase de desenvolvimento e de criação de hábitos que podem perdurar ao longo da vida.

As bibliotecas precisam oferecer diversos recursos bibliográficos a fim de atuarem como locais de aprendizagem. Para isso é necessário que os materiais bibliográficos, principalmente de bibliotecas escolares, devem ser apropriados para a idade dos alunos e de acordo com o perfil de seus usuários. As bibliotecas infantis precisam de materiais bibliográficos de acordo com a idade dos seus alunos, principalmente literaturas condizentes com sua faixa etária.

È importante considerar novas formas de catalogação no ambiente escolar, pois este é o público que está começando a aprender a pesquisar e se eles forem orientados corretamente, poderão utilizar o acervo de qualquer biblioteca.Uma das formas da biblioteca apresentar qualidade é desenvolver normas simplificadas de organizaçao e classificação e que estas sejam amplamente divulgadas para que os 
usuários possam buscar as iformaçoes sozinhas.

As fichas de registro de leitura para a organizaçao das Horas do Conto se torna um instrumento para que o mediador possa refletir sobre sua prática, ampliála, readequá-la e melhorar o acesso do aluno à informação.

É fundamental que este ambiente tenha um educador capacitado e que entenda a importância de ser leitor desde o início da formação escolar proporciona um contato maior e valoriza as atividades de leitura promovidas na escola. Ao incentivar o hábito da leitura na biblioteca escolar, este educador movimenta o seu local de trabalho, enaltecendo sua importância e também valorizando as atividades que devem ser desenvolvidas para que a leitura seja uma constante no cotidiano dos alunos e dos demais educadores.

Uma biblioteca bem equipada e um profissional capacitado conseguirá atingir o objetivo de mediar a leitura no ambiente escolar de forma eficaz a formar leitores críticos e que possam motivar outras pessoas a serem leitores.

\section{REFERÊNCIAS}

BARBOSA, S.; MEY, E.S.S.; SILVEIRA, N. C. Vocabulário controlado para indexação de obras ficcionais. Brasília: Briquet de Lemos, 2005

BARROS, Maria Helena Toledo Costa de. Leitura do adolescente: uma interpretação pelas bibliotecas públicas do Estado de São Paulo - pesquisa trienal. Marília: UNESP, 1995.

BICHERI, Ana Lúcia Antunes de Oliveira; ALMEIDA JÚNIOR, Oswaldo Francisco. Bibliotecário escolar: um mediador de leitura. Biblioteca Escolar em Revista, Ribeirão Preto, v. 2, n. 1, p. 41-54, 2013. Disponível em: <http://revistas.ffclrp.usp.br/BEREV/article/viewFile/257/pdf>. Acesso em: 06 ago. 2013.

BRASIL. Secretaria de Educação Fundamental.Parâmetros curriculares nacionais: língua portuguesa /Secretaria de Educação Fundamental. - Brasília, 1997.

GARCIA, Edson Gabriel. A Leitura na escola de 1ำ grau: por uma outra leitura da leitura. 2. ed. São Paulo: Editora Loyola, 1992. 
IFLA. Manifesto da IFLA/Unesco para biblioteca escolar. Tradução de Neusa Dias de Macedo. IFLA, 2005. Disponível em: <http://www.ifla.org/files/assets/schoollibraries-resource-centers/publications/school-library-guidelines/school-libraryguidelines-pt.pdf>. Acesso em 15. jul.2013.

LAJOLO, Marisa. O texto não é pretexto. In: ZILBERMAN, Regina (Org.). Leitura em crise na escola: as alternativas do professor. Porto Alegre: Mercado Aberto, 1986.

MARTINS, Elizandra; BORTOLIN, Sueli. O bibliotecário escolar "afinando" o foco na leitura. In: SILVA, Rovilson José da; BORTOLIN, Sueli (Org.). Fazeres cotidianos na biblioteca escolar. São Paulo: Polis, 2006. p. 33-42. (Coleção Palavra-Chave, v.17).

MENEGOLLA, Maximiliano; SANT'ANA; Ilza Martins. Porque Planejar? Como Planejar? Currículo e Área-Aula. 11. ed. Petrópolis: Vozes. 2001.

SILVA, Ezequiel Theodoro da. Democratização da leitura: uma forma de despertar leitores. In: Conferências sobre leitura: trilogia pedagógica. Campinas: Autores Associados, 2003.

SILVA, Ezequiel Theodoro da. O Professor e o Combate à Alienação Imposta. São Paulo: cortez: Autores Associados,1991.

SIMÃO, Maria Antonieta Rodrigues; SCHERCHER, Eroni Kern; NEVES, lara Conceição Bitencourt. Ativando a biblioteca escolar. Porto Alegre: Sagra-DC Luzzato, 1993.

WARSCHAUER. C. A Roda e o Registro. Rio de Janeiro: Paz e terra, 1993. ZILBERMAN, Regina. A literatura infantil na escola. 11. ed. São Paulo: Global, 2003

Title

School library and reading mediation: a proposal for catalog books.

\section{Abstract}

Introduction: This article handles the social and academic education of the School Library educator and her contribution to the development of reading mediation practices for reader's education.

Objective: Check how the school library, its pedagogical organization and the storytelling contribute to the formation of readers.

Methodology: The bibliographic research of documentary method based on personal papers written and on official papers, aiming to verify the education of the individual, the school library and the pedagogical organization of storytelling contribute to the reader's 
education. This research is guided by: Silva, Lajolo, Zilberman, whom conceptualize reading and UNESCO and Barbosa et al. papers regarding School Library organization.

Results: As a result of this research obtained a bibliographic record sheet as assistance in the continuing education of library educator for all school educators can use the books in the classroom at the time of storytelling and therefore expand their practice in a reading mediation

Conclusions: It is concluded what the teacher of the school library has a function to intermediate the student's learning process, stimulating him/her to be a diligent reader and presenting literature that contributes to his/her growth as reader, it is important to highlight that the library environment must be suitable to accommodate this reader, providing approximation the reader with book.

Keywords: School library. Reading mediation. Formation reader. Bibliographic record.

\section{Título}

Biblioteca escolar y la mediación de lectura: una propuesta de hojas de registro bibliográfico

\section{Resumen}

Introducción: Este artículo aborda La formación social y acadêmica del educador Biblioteca escolar y su contribución al desarrollo de la lectura de las prácticas de mediación para la formación del lector a través de la biblioteca de la escuela.

Objetivo: Compruebe cómo la biblioteca de la escuela, su organización pedagógica y la narración de cuentos contribuyen a la formación del lectores.

Metodología: La naturaleza bibliográfica del método de investigación documental sobre la base de documentos personales, escritos y documentos oficiales destinados a ver cómo la formación de la persona, la biblioteca de la escuela y la organización pedagógica de la narración de cuentos contribuyen a la formación de lectores. Subyacen a las concepciones de la investigación: Silva, Lajolo, Zilberman que conceptualizan la lectura; documentos de la UNESCO y Barbosa et al. sobre la organización de la biblioteca de la escuela.

Resultados: Como resultado de esta investigación se obtuvo una hoja de registro bibliográfico como una ayuda en la continuación de educador biblioteca de formación para todos los educadores de las escuelas pueden utilizar los libros en el aula en el momento de la narración historias y así ampliar su enseñanza de la lectura de la mediación.

Conclusiones: Se concluye que el maestro de la biblioteca de la escuela sirve para mediar en el aprendizaje de le studiante, animándole a leer y ofreciéndo le la literatura que contribuyen a sudesarrollo como jugador, hay que destacar que el entorno físico de la biblioteca debe ser adecuado para recibir esta lector a lo que desencadena aproximación do lector com lo livro.

Palabras clave: Biblioteca escolar. Mediación de lectura. Formación del lector. Registro bibliográfico.

Recebido em: 12.11 .2014

Aceito em: 22.12.2014 